\title{
PERBEDAAN LAJU PERTUMBUHAN KARANG Porites lutea DI PULAU TUNDA
}

\author{
THE DIFFERENCE EXTENSION RATE OF CORAL Porites lutea AT TUNDA ISLAND
}

\author{
Lalang $^{1}$, Neviaty P. Zamani ${ }^{2}$, Ali Arman ${ }^{2}$ \\ ${ }^{1}$ Program Studi Ilmu Kelautan, Sekolah Pascasarjana, \\ ${ }^{2}$ Departemen Ilmu dan Teknologi Kelautan \\ Fakulltas Perikanan dan Ilmu Kelautan, Institut Pertanian Bogor \\ ${ }^{3}$ Pusat Aplikasi Isotop dan Radiasi, BATAN \\ Korespondensi : lalang_msp_08@yahoo.com
}

\begin{abstract}
The skeleton of deposited coral species Porites lutea can provide information to determine the life growth rate of the coral that can be seen on its annual bands. The coral sampling was carried out by using pneumatic drill and then it was analyzed to determine the direction, age, and growth rates of the coral, using X-ray. Result of the research showed that the growth rate of Porites lutea coral in northern station (windward) was in ranged of $0.60-2.50 \mathrm{~cm} /$ year while the average growth rate was $1.44 \mathrm{~cm} /$ year, and in the southern station (leeward) was in ranged of $0.50-2.20 \mathrm{~cm} /$ year while its average growth rate was $1.21 \mathrm{~cm} /$ year. The growth rate of Porites lutea both located north station (winward) and the south station (leeward) showed no significant difference.
\end{abstract}

Keywords: growth extension linear, Porites lutea, Tunda island, X-ray

\begin{abstract}
ABSTRAK
Kerangka karang pada jenis karang Porites lutea yang telah terdeposit dapat memberikan informasi dalam menentukan laju pertumbuhan karang yang terlihat pada lingkar tahunan (annual band). Pengambilan sampel dilakukan dengan cara pemboran dengan menggunakan mata bor pneumatic yang selanjutnya dianalisis menggunakan sinar-x untuk mendapatkan arah, umur dan laju pertumbuhan. Hasil penelitian menunjukkan pertumbuhan karang Porites lutea yang berada pada stasiun utara (windward) berkisar antara $0.60-2.50 \mathrm{~cm} /$ tahun dengan laju pertumbuhan rata-rata $1.43 \mathrm{~cm} /$ tahun, dan stasiun selatan (leeward) berkisar antara $0.50-2.20 \mathrm{~cm} /$ tahun dengan laju pertumbuhan rata-rata sebesar $1.21 \mathrm{~cm} /$ tahun. Laju pertumbuhan karang Porites lutea baik yang berada stasiun utara (winward) maupun stasiun selatan (leeward) menunjukkan tidak berbeda nyata.
\end{abstract}

Kata kunci: laju pertumbuhan, Porites lutea, Pulau Tunda, sinar-X

\section{PENDAHULUAN}

Keberadaan karang batu (massive) dapat memberikan manfaat yang besar sebagai habitat berbagai jenis biota penghuni daerah terumbu karang, dan sekaligus berfungsi sebagai tempat memijah, membesarkan diri, berlindung, dan sebagai tempat mencari makan. Karang batu sebagai penghasil kalsium karbonat $\left(\mathrm{CaCO}_{3}\right)$ memberikan manfaat berupa penyerapan pemanasan global sebesar 7-15\% (Suzuki et al. 2004). Terumbu karang merupakan tempat hidup bagi berbagai biota laut tropis lainnya, sehingga terumbu karang memiliki keanekaragaman jenis biota tinggi dan sangat produktif (Suharsono 1996).

Pertumbuhan karang merupakan pertambahan panjang linear, bobot, volume atau luas kerangka kapur dalam kurun waktu tertentu. Secara umum, pembentukan kerangka karang diinterpretasikan sebagai kenaikan bobot kerangka karang yang disusun oleh kalsium karbonat dalam bentuk aragonite kristal dan kalsit (CarricartGanivet \& Barnes 2007). Laju pertumbuhan karang dapat diukur dengan berbagai cara yaitu pengukuran pertambahan panjang linear, area, volume, atau bobot kerangka kalsiumnya dengan menggunakan metode restropektif (pengukuran ke belakang). Pengamatan tersebut membutuhkan waktu yang lama, namun dengan menggunakan sinar-X dapat dengan mudah diketahui laju pertambahan linear karang khususnya karang-karang keras seperti Porites yang terlihat dalam annual band (pita tahunan) yang ada pada kerangka terumbu (Buddemeier et al. 1974).

Karang masif dapat tumbuh dan mengendapkan kalsium karbonat pada lapisan jaringan yang kecil pada 
permukaan luar koloninya (Crabbe 2008). Kepadatan yang ditemukan setara dengan pertumbuhan setiap tahunnya (Knuston et al. 1972). Struktur kerangka pada karang akan terlihat garis tahunan (annual band) yang dapat memberikan informasi penting mengenai laju pertumbuhan dan kondisi lingkungan di mana karang tersebut hidup (Carricart-Ganivet et al. 2007). Beberapa penelitian yang telah dilakukan di Indonesia khususnya di daerah Karimun Jawa dan Bangkalan diperoleh laju pertumbuhan karang Porites berkisar 5.38-17 mm/tahun dengan umur 4-8 tahun, dan persentase pertumbuhan tiap-tiap koloni berbeda-beda (Nugraha 2008). Kerangka karang yang berada pada koloni karang yang berukuran besar dapat memberikan informasi mengenai variasi kepadatan pada setiap tahunnya yang dapat diamati dengan menggunakan sinar-X melalui irisan kerangka yang telah dipotong pada posisi vertikal (Knutson et al. 1972).

Perbedaan lokasi tempat hidup terumbu karang pada daerah terbuka maupun daerah terlindung memberikan pengaruh pada proses pertumbuhan, hal ini berkaitan dengan pergerakan arus dan gelombang serta perubahan lingkungan yang ekstrim seperti letusan gunung berapi (Johnson et al. 2014). Suhu permukaan laut berperan penting dalam pertumbuhan karang (Crabbe 2008). Suhu yang optimal dapat dimanfaatkan oleh hewan karang untuk tumbuh dan berkembang dengan baik, namun perubahan suhu akan menghambat laju pertumbuhan karang Porites lutea karena dapat mengkibatkan karang kehilangan alga simbion (zooxanthallae) apabila dapat menoleransi perubahan suhu yang ekstrim (Chen et al. 2013). Penelitian ini bertujuan untuk menentukan laju pertumbuhan karang Porites lutea serta melihat perbedaan laju pertumbuhan baik yang berada pada stasiun utara (windward) maupun stasiun selatan (leeward).

\section{METODE PENELITIAN}

Pengambilan sampel dilakukan pada bulan Agustus tahun 2014 yang berlokasi di Pulau Tunda, Kecamatan Karang Anyer, Kabupaten Serang, Provinsi Banten. Sampel dianalisis pada bulan Agustus-Oktober tahun 2014 di laboratorium Pusat Aplikasi Isotop dan Radiasi, Balai Teknologi Nuklir Nasional (BATAN) Jakarta. Pemilihan lokasi dan stasiun berdasarkan keterwakilan area (windward dan leeward), dan sebaran karang Porites lutea. Pengambilan sampel pada penelitian ini dilakukan pada dua lokasi yaitu stasiun utara pada daerah terbuka dan stasiun selatan pada daerah terlindung. Lokasi ditunjukan pada Gambar 1.

Pemilihan lokasi dan stasiun berdasarkan keterwakilan area (windward dan leeward), dan sebaran karang Porites lutea. Pengambilan sampel pada penelitian ini dilakukan pada dua lokasi yaitu stasiun utara pada daerah terbuka dan stasiun selatan pada daerah terlindung. Metode yang digunakan dalam melakukan pengambilan sampel menggunakan mata bor pneumatic, dimana mata bor dihubungkan dengan tabung udara selam sebagai penggerak mata bor yang terbuat dari stainless steel. Diameter mata bor yang digunakan adalah $5 \mathrm{~cm}$ dengan panjang $50 \mathrm{~cm}$ namun dapat diperpanjang dengan sambungan sehingga dapat digunakan untuk pengambilan sampel sampai $3 \mathrm{~m}$ (Arman et al. 2013). Pengeboran karang dilakukan secara vertikal untuk mendapatkan arah dan laju pertumbuhan yang kontinu. Pada saat karang dibor air dialirkan dengan menggunakan pompa yang dilewatkan melalui bagian dalam pipa stainless steel yang berfungsi untuk mengeluarkan butir-butir halus sisa karang akibat dari pengeboran, hal ini dilakukan untuk menghindari terjadinya macet pada perputaran mata bor. Selanjutnya setelah selesai pengambilan sampel, bekas lubang bor ditutup dengan menggunakan semen, untuk menghindarikerusakan pada terumbu oleh biota yang lain. Sampel dicuci dengan menggunakan air tawar, dikeringkan, dan dimasukkan di laboratorium untuk dianalisis.

Proses analisis dilakukan dengan memotong sampel menjadi bentuk lempengan (slab), memanjang dari atas ke bawah dengan ketebalan $5 \mathrm{~mm}$ menggunakan mesin pemotong sampel. Sebelum sampel dianalisis terlebih dahulu dibersihkan dalam ultrasonic bath yang diulang sebanyak 3 (tiga) kali untuk menghilangkan sisa potongan karang yang menempel di permukaan dan juga kontaminan lainnya. Selanjutnya, sampel yang berupa lempengan di analisis dengan radiografi sinar- $X$ dengan menggunakan generator Rigaku Radioflex RF-300 EGM2 $130 \mathrm{ke}-\mathrm{V}$ dengan lama penyinaran 1 detik dan jarak $1 \mathrm{~m}$ dari sampel. Setelah itu, dilakukan proses pencucian di ruang gelap untuk memperoleh hasil film positif pada kerangka terumbu karang. Film positif selanjutnya diubah menjadi format digital menggunakan scanner film positif (Epson V 600)

Data suhu permukaan laut diperoleh dari citra satelit yang diterbitkan ERDDAP (Easier Access to Scientific Data) yang selanjutnya dianalisis dengan menggunakan software Ocean Data View 4 (ODV 4). Data suhu permukaan laut yang berhasil dikumpulkan dimulai pada tahun 1981 sampai 2014 yang digunakan sebagai perameter pendukung dalam menentukan laju pertumbuhan karang Porites lutea. Data Laju pertumbuhan dianalisis dengan menggunakan software Coral XDS (Helmle et al. 2012), sedangkan untuk menentukan beda nyata menggunakan software SPSS 16 . 


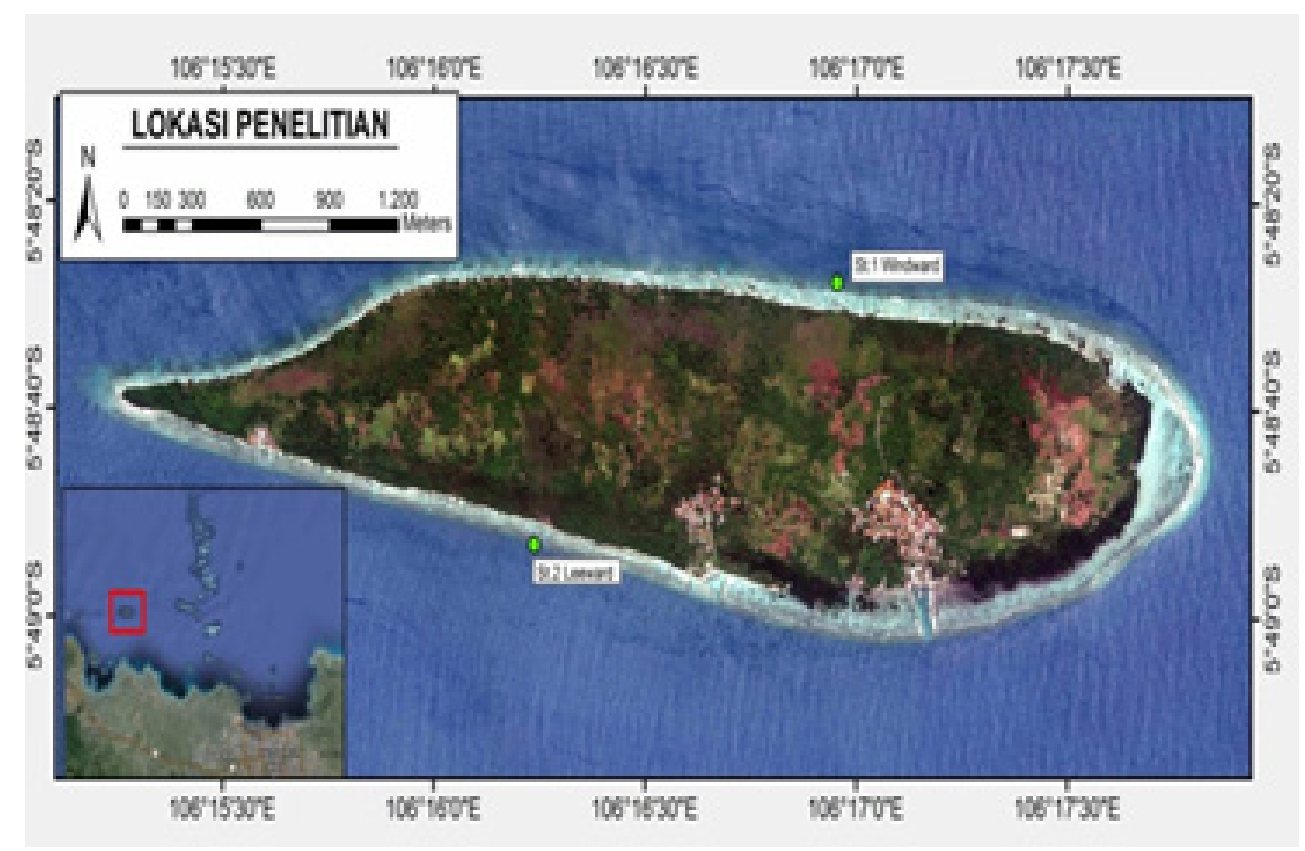

Gambar 1. Lokasi penelitian

\section{HASIL DAN PEMBAHASAN}

\section{Laju Pertumbuhan Karang Porites lutea pada Stasiun Utara (Windward)}

Karang memiliki laju pertumbuhan yang beragam khususnya pada karangkarang keras seperti Porites, hal ini disebabkan karena karang Porites dapat bertahan hidup pada kondisi lingkungan yang ekstrim. Perubahan kondisi lingkungan menyebabkan karang mengalami perubahan bentuk pertumbuhan yang berbeda dengan pertumbuhan sebelumnya (Carricart-Ganivet 2004). Laju pertumbuhan linear karang Porites lutea yang dipengaruhi oleh kondisi lingkungan maupun habitat karang dapat terekam pada kerangka kapur yang telah terdeposit yang dilihat dengan menggunakan sinar-X (Kenkel et al. 2013).

Garis tahunan yang terdapat pada karang Porites lutea (Gambar 2) dapat dijadikan sebagai acuan dalam menentukan laju pertumbuhan linear, dan umur karang, serta melihat perubahan lingkungan yang terjadi yang terekam pada kerangka terumbu sehingga dapat menduga pengaruh kondisi lingkungan terhadap laju pertumbuhan terumbu yang ada pada karang Porites lutea.

Hasil pengukuran dari sampel yang didapatkan (Gambar 3) menunjukkan laju pertumbuhan karang Porites lutea yang berada pada stasiun utara berkisar 0.60-2.50 $\mathrm{cm} /$ tahun dengan umur selama 76 tahun dan laju pertumbuhan rata-rata sebesar $1.44 \mathrm{~cm} /$ tahun, dimana pertumbuhan karang Porites lutea yang tertinggi terdapat pada tahun 1940 dan 1951 yaitu $2.50 \mathrm{~cm} /$ tahun sedangkan laju pertumbuhan yang terendah terdapat pada tahun 1998 yaitu $0.60 \mathrm{~cm} /$ tahun.

Laju pertumbuhan linear (Gambar 4) yang terdapat pada stasiun selatan (leeward) berkisar 0.50-2.10 cm/tahun, dengan umur selama 47 tahun serta laju pertumbuhan rata-rata sebesar $1.21 \mathrm{~cm} /$ tahun. Pertumbuhan tertinggi terdapat pada tahun 1971 sebesar $2.10 \mathrm{~cm} /$ tahun dan terendah terdapat pada tahun 1998 sebesar $0.50 \mathrm{~cm} /$ tahun dari sampel yang didapatkan. Penyebab penurunan laju pertumbuhan karang Porites lutea pada tahun 1998 dikarenakan terjadi kenaikan suhu permukaan laut. Pertumbuhan karang Porites Lutea baik yang berada pada stasiun utara (windward) maupun yang berada pada stasiun selatan (leeward) cenderung mengalami penurunan laju pertumbuhan.

Hasil analisis data menunjukkan laju pertumbuhan karang Porites lutea, baik yang berada pada stasiun utara (windward) maupun yang berada pada stasiun selatan (leeward) menunjukkan tidak berbeda (sig > 0.05).

\section{Laju pertumbuhan karang Porites lutea kaitannya dengan kenaikan suhu permukaan laut}

Peningkatan suhu permukaan laut (Gambar 5) yang terjadi pada tahun 1983 dengan suhu sebesar $29.33^{\circ} \mathrm{C}$ menyebabkan karang Porites lutea dapat tumbuh sebesar 
$0.90 \mathrm{~cm} /$ tahun pada stasiun utara dan sebesar $0.90 \mathrm{~cm} /$ tahun pada stasiun selatan, peningkatan suhu permukaan laut yang terjadi pada tahun 1998 dengan suhu sebesar $29.57{ }^{\circ} \mathrm{C}$ menyebabkan penurunan laju pertumbuhan dengan kemampuan tumbuh sebesar $0.60 \mathrm{~cm} /$ tahun untuk stasiun utara dan sebesar $0.50 \mathrm{~cm} /$ tahun pada stasiun selatan, dan kenaikan suhu pada tahun 2010 dengan suhu permukaan laut sebesar 29.61 ${ }^{\circ} \mathrm{C}$ dimana karang Porites lutea tumbuh sebesar $0.70 \mathrm{~cm} /$ tahun pada stasiun utara dan sebesar $0.60 \mathrm{~cm} /$ tahun pada stasiun selatan dari kisaran pertumbuhan normal sebesar 1.00-2.50 $\mathrm{cm} /$ tahun. Penurunan laju pertumbuhan yang terjadi secara signifikan terdapat pada tahun 1998. Hal ini diakibatkan suhu permukaan laut mengalami peningkatan secara signifikan dari tahun sebelumnya (Arman et al. 2013). Beberapa penelitian yang telah dilakukan mengenai laju pertumbuhan karang Porites lutea baik yang ada di Thailand Selatan maupun yang ada di Great Barrief Reef Australia telah mengalami penurunan laju pertumbuhan akibat dari kenaikan maupun penurunan suhu permukaan laut (Lough \& Barnes 2000).

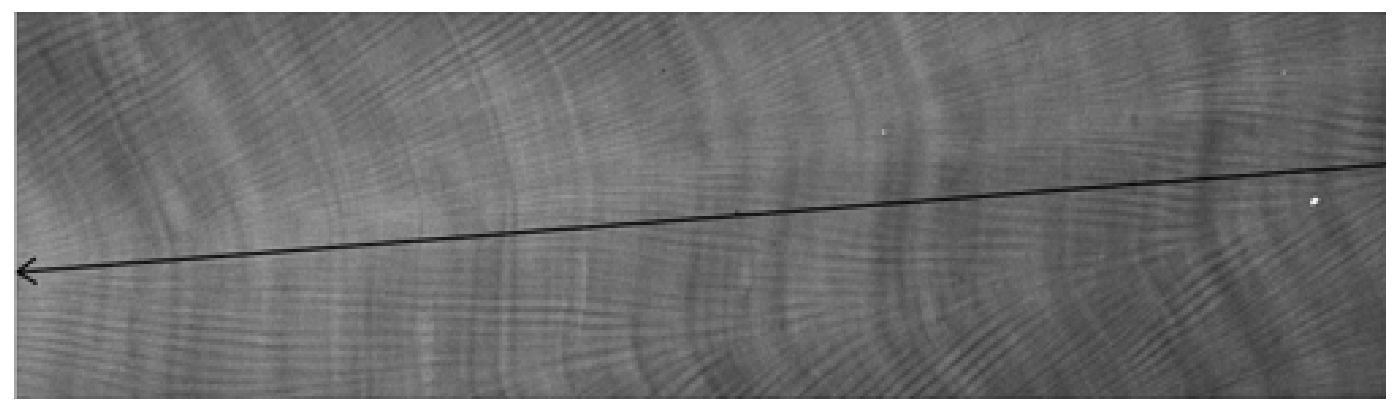

Gambar 2. Hasil analisis laju pertumbuhan karang Porites lutea Pulau Tunda menggunakan sinar-X

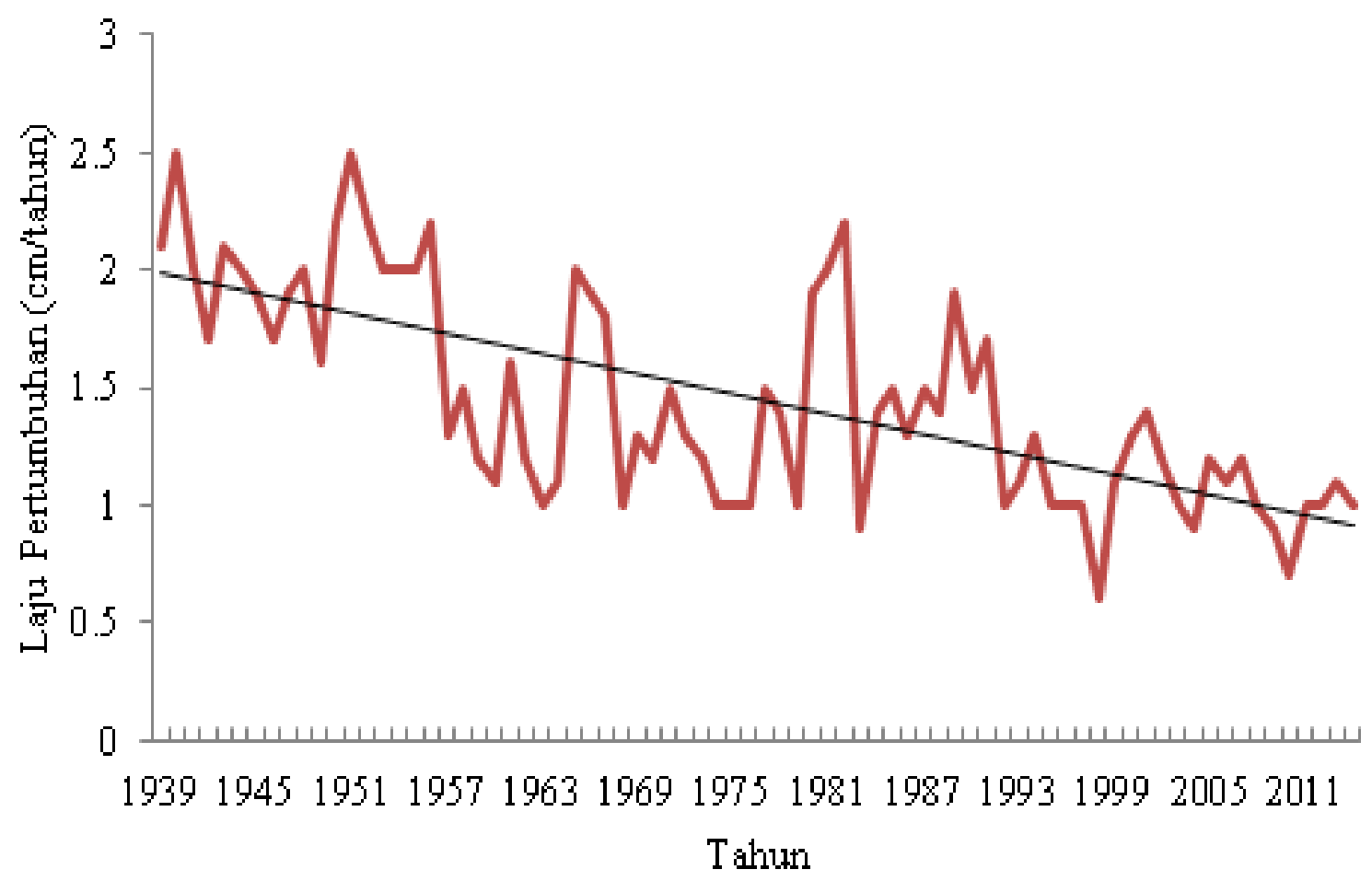

Gambar 3. Laju pertumbuhan linear karang Porites lutea stasiun utara 


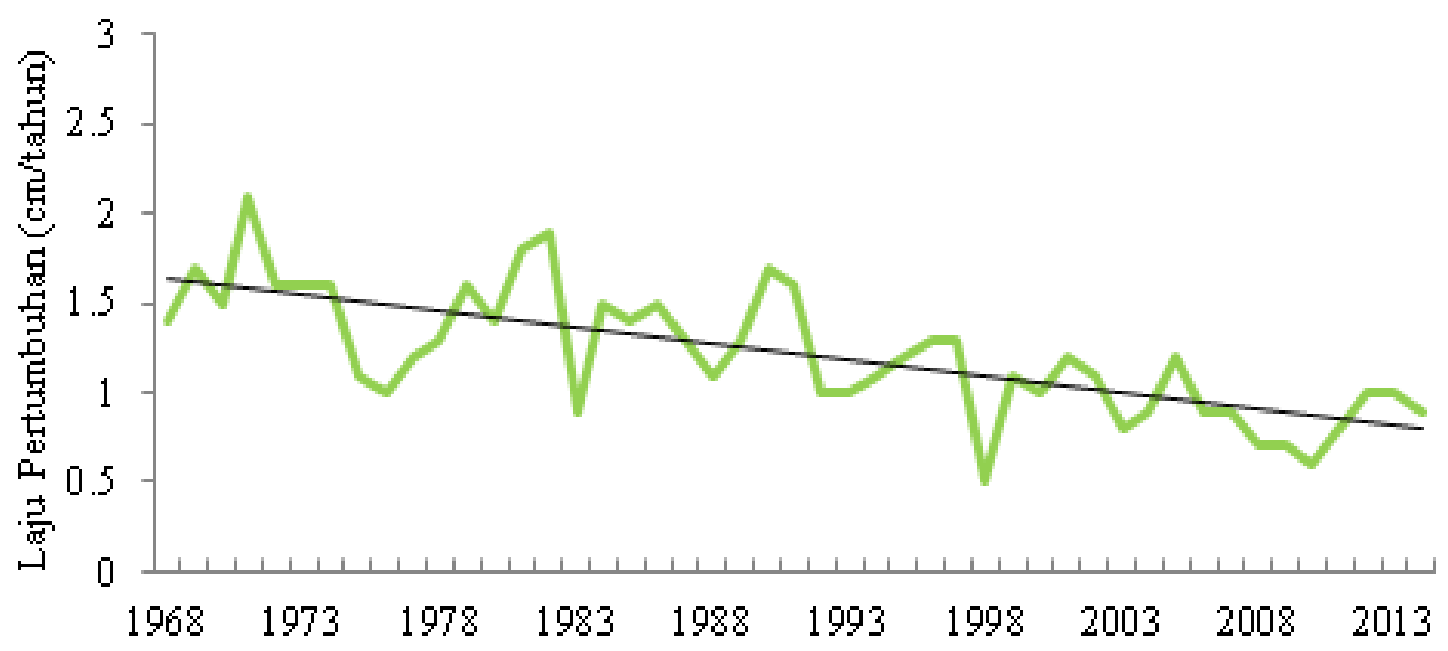

Tahun

Gambar 4. Laju pertumbuhan linear Porites lutea stasiun selatan

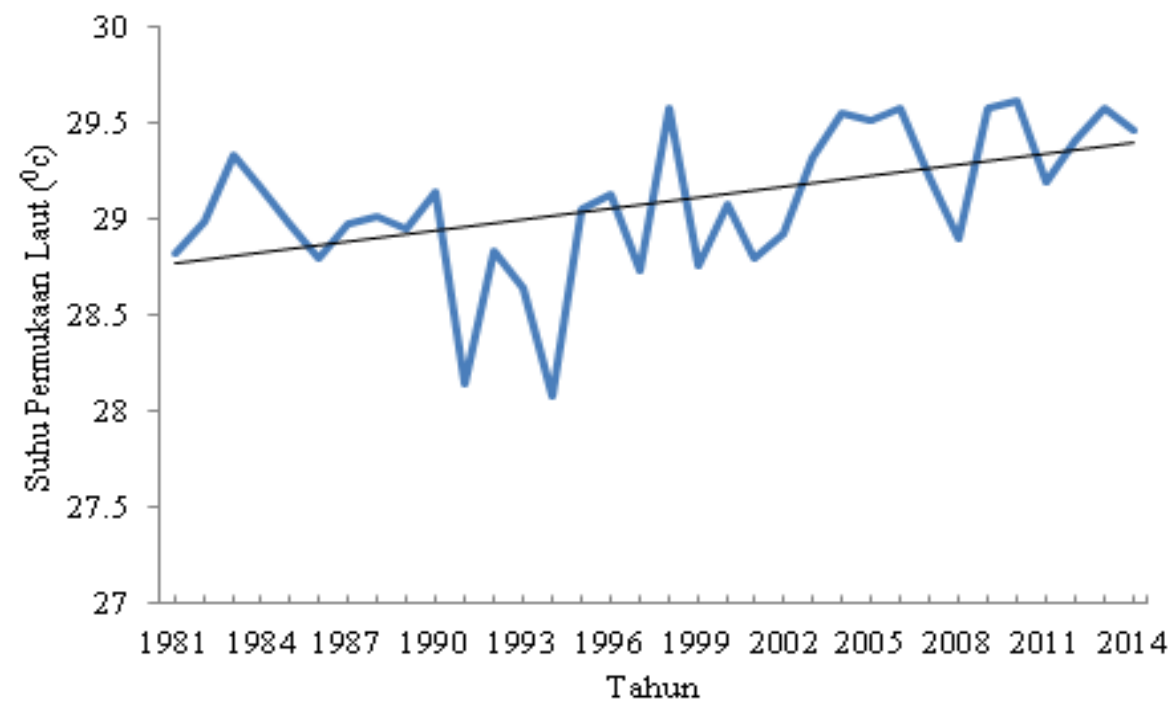

Gambar 5. Suhu permukaan laut

\section{KESIMPULAN}

Laju pertumbuhan linear karang Porites lutea baik yang berada pada stasiun utara (winward) maupun yang berada pada stasiun selatan (leeward) menunjukkan tidak berbeda nyata.

\section{DAFTAR PUSTAKA}

Arman A, Zamani NP, Watanabe T. 2013. Studi penentuan umur dan laju pertumbuhan terumbu karang terkait dengan perubahan iklim ekstrim menggunakan sinar-x. A Scientific Journal for the Applications of Isotopes and Radiation. 9:1-10.
Buddemeier, Maragos RWJE, Knutson DW. 1974. Radiographic studies of reef coral exoskeletons: rates and patterns of coral growth. J. Exp. Mar. Biol. Ecol. 14:179-200.

Carricart-Ganivet JP. 2004. Sea surface temperature and the growth of the west atlantic reef-building coral montastraea annularis. J. Exp. Mar. Biol. Ecol. 302(2):249-260.

Carricart-Ganivet PJ, Lough MJ, Barnes JD. 2007. Growth and luminescence characteristics in skeletons of massive porites from a depth gradient in the central great barrier reef. J. Exp. Mar. Biol. Ecol. 351:27-36. 
Carricart-Ganivet PJ, Barnes JD. 2007. Densitometry from digitized images of x-radiographs: methodology for measurement of coral skeletal density. Exp. Mar. Biol. Ecol. 344:67-72.

Chen T, Kefu Y, Chen T. 2013. Sr/ca-sea surface temperature calibration in the coral porites lutea from subtropical northern south china sea. J. Palaeo. 392:98-104.

Crabbe MJC. 2008. Climate change, global warming and coral reefs: modelling the effects of temperature. Comput. Biol. Chem. 32(5):311-314.

Helmle KP, Kohler KE, Dodge RE. 2012. Relative optical densitometry and the coral x-radiograph densitometry system: coral xds. Presented poster (omitted from abstract book, but included in program). Int. Soc. Reef Studies European Meeting. Cambridge, England. Sept. 4-7.

Johnson ME, Ramalho RS, Baarli BG, Cachão M, da Silva CM, Mayoral EJ, Santos A. 2014. Miocene-pliocene rocky shores on são nicolau (cape verde islands): contrasting windward and leeward biofacies on a volcanically active oceanic island. J. Palaeo. 395:131-143.
Kenkel CD, Goodbody GG, Caillaud D, Davies SW, Bartels E, Matz M. 2013. Evidence for a host role in thermotolerance divergence between populations of the mustard hill coral (Porites astreoides) from different reef environments. Mol Ecol. (16):4335-48. DOI: 10.1111/ mec. 12391.

Knutson RW, Buddemeier, Smith SV. 1972. Coral chronometers: seasonal growth bands in reef corals. Science. 177: 270-272.

Lough DJ, Barnes DJ. 2000. Environmental controls on growth of the massive coral porites. Exp. Mar. Biol. Ecol. 245:225243

Nugraha WA. 2008. Laju pertumbuhan karang Porites lutea di Karimun Jawa, dan Bangkalan, Indonesia. Embryo. 5:1-10.

Suharsono. 1996. Jenis-jenis karang yang umum di jumpai di Indonesia. P3O LIPI, Jakarta.

Suzuki AH, Kawahata H, Shiyomi M, Koizumi H, Tsuda A, Awaya Y. 2004. Characterization of ocean productivity using a new physical biological coupled ocean model. Global Environmental Change in the Ocean and on Land. $1-44$. 